\title{
Development of Discriminative Dissolution Media for Marketed Gliclazide Modified-Release Tablets
}

\author{
M. Bala Vishnu Priya* and T.E. G. K. Murthy \\ Dept. of Pharmaceutics, Bapatla College of Pharmacy, Bapatla, Guntur, Andhra Pradesh, India
}

\begin{abstract}
In vitro release studies were performed for three commercial, modified-release brands of the anti-diabetic drug gliclazide at 30-mg strength. Dissolution media such as $0.1 \mathrm{~N} \mathrm{HCl}(\mathrm{pH} 1.2)$, acetate buffer $(\mathrm{pH} 4.5)$, distilled water (pH 7.0), and phosphate buffer ( $\mathrm{pH}$ 7.4) were evaluated to develop a dissolution method for better evaluation of gliclazide formulations, as there was no official method for gliclazide modified-release tablets. Drug release followed zero-order kinetics in all dissolution media except acetate buffer, where it followed first-order kinetics. The statistically treated data show a significant difference in release rates among the brands. The similarity factor and difference factor values also show the adjustment of differences in release profiles. The drug release studies carried out in $0.1 \mathrm{~N} \mathrm{HCl}$ show that this medium is the most suitable for providing sink conditions and discriminating conditions.
\end{abstract}

\section{INTRODUCTION}

$$
\text { T'song }
$$

he release of active pharmaceutical ingredient from drug product, the dissolution of the drug under physiological conditions, and the permeability across the gastrointestinal tract determine drug absorption. Based on this, in vitro dissolution may be vital in assessing in vivo performance. Dissolution testing serves as a tool to distinguish between acceptable and unacceptable products. It is also used to assess the lot-to-lot quality of a drug product and can guide the development of new formulations. In the pharmaceutical industry, regulatory agencies often require discriminating dissolution methods. As product development continues at increasingly faster rates, dissolution method development must be able to keep pace with an increasing number of products. Dissolution scientists face great challenges in developing discriminating dissolution methods.

The development of a dissolution procedure involves selecting the dissolution medium, apparatus, and agitation rate appropriate to the product. The solubility of the active ingredient(s) is one of the key aspects in the screening of possible dissolution media. A slow stirring speed $(50 \mathrm{rpm})$ may represent the most appropriate operating condition that allows maximum discriminatory power. However, use of a low rotation speed could result in a lack of robustness in the data due to poor hydrodynamics in the dissolution vessel and can more reflect system artifacts such as coning rather than true formulation changes. In most cases, a dissolution apparatus tends to become less discriminating when operated at higher stirring speeds ( 75 or $100 \mathrm{rpm}$ ) that result in flatter drug release profiles. In some cases, increased stirring speeds result in a method with a higher discriminating power by reducing the variability of the data and more accurately

*Corresponding author. reflect true formulation or manufacturing changes or processes. The final dissolution procedure selected should be robust and able to distinguish small changes in the product formulation (1).

Gliclazide is a second-generation hypoglycemic sulfonylurea used in the treatment of non-insulin-dependent diabetes mellitus (NIDDM). Gliclazide is classified as a Class 2 drug (poor solubility and high permeability) according to the Biopharmaceutics Classification System (BCS). The conventional formulation requires twice-daily administration. Once-daily, modified-release gliclazide (30-120 mg) was as effective as twice-daily gliclazide (80-320 mg) in reducing glycosylated hemoglobin $(\mathrm{HbA} 1 \mathrm{C})$ with fewer side effects and less risk of hypoglycemia (2-4).

In the present study, three marketed brands of gliclazide MR tablets (30 mg) were subjected to in vitro drug release studies over the physiological $\mathrm{pH}$ range (i.e., 1.2-7.4) with different basket stirring speeds to identify the sink and discriminative conditions.

\section{EXPERIMENTAL}

\section{Materials and Methods}

The marketed brands of gliclazide of 30-mg strength (Azukon, Nuzide, and Diamicron) were procured from the commercial market. Hydrochloric acid, sodium acetate, glacial acetic acid, potassium dihydrogen phosphate, and sodium hydroxide (Qualigens, Mumbai) were used. Distilled water was used throughout the study. USP dissolution Apparatus 1 (ELICO) and a UV-vis spectrophotometer (Shimadzu) were used.

\section{Saturation Solubility Study}

The saturation solubility studies of gliclazide were conducted as per BCS guidelines. A single-dose strength (30 mg) of gliclazide was added to $250 \mathrm{~mL}$ of each medium (0.1 N HCl pH 1.2, acetate buffer pH 4.5, distilled water pH 7.0, and phosphate buffer $\mathrm{pH} 7.4$ ), placed in $500-\mathrm{mL}$ conical flasks, 
Table 1. Solubility Studies and Sink Conditions of Gliclazide in Different Fluids

\begin{tabular}{lcc}
\hline Buffer employed & Solubility $(\mathbf{m g} / \mathbf{m L})$ & $\begin{array}{c}\text { Sink conditions } \\
\left(\boldsymbol{C}_{\mathrm{s}} / \boldsymbol{C}_{\mathrm{d}}\right)\end{array}$ \\
\hline $0.1 \mathrm{~N} \mathrm{HCl} \mathrm{pH} \mathrm{1.2}$ & 1.694 & 50.82 \\
\hline Acetate buffer pH 4.5 & 0.0335 & 1.005 \\
\hline Distilled water pH 7.0 & 0.3485 & 10.455 \\
\hline Phosphate buffer pH 7.4 & 1.8415 & 55.245 \\
\hline
\end{tabular}

$C_{s}$ : Saturation solubility of gliclazide in $900 \mathrm{~mL}$ of dissolution medium. $C_{\mathrm{d}}$ : Dose of gliclazide in MR tablet formulation (30 mg).

and agitated continuously at room temperature for $48 \mathrm{~h}$ on a mechanical shaker. The saturated solutions were then filtered through Whatman filter paper (no.41), suitably diluted, and analyzed spectrophotometrically at $235 \mathrm{~nm}$.

\section{In Vitro Drug Release Studies}

Three different brands of 30-mg gliclazide MR tablets (i.e., Azukon, Nuzide, and Diamicron designated A, B, and C, respectively) were procured for comparative dissolution studies. The in vitro dissolution studies were performed on dissolution tester TDT-08L (THAI-MAHAL Advance Technology Co., Ltd.) using USP Apparatus 1 with $900 \mathrm{~mL}$ of medium at $37 \pm 0.5^{\circ} \mathrm{C}$. Stirrer speeds were 50,75 , and $100 \pm 2$ rpm for phosphate buffer IP (pH 7.4) and $100 \pm 2$ rpm for $0.1 \mathrm{~N} \mathrm{HCl} \mathrm{IP} \mathrm{(pH} \mathrm{1.2),} \mathrm{acetate} \mathrm{buffer} \mathrm{USP} \mathrm{(pH} \mathrm{4.5),}$ and distilled water ( $\mathrm{pH} 7.0)$. These media were selected based on the FDA guidance for industry (5-7). Then at regular intervals (30 $\mathrm{min}$ ), $5-\mathrm{mL}$ samples were collected, and the same volume was replenished with fresh dissolution medium. The withdrawn samples were filtered through Whatman filter paper (no.41), suitably diluted, and analyzed spectrophotometrically at a $\lambda$ max of $235 \mathrm{~nm}$.

\section{Comparison of Dissolution Profiles by Model-Independent Method}

A simple model-independent approach using a difference factor $\left(f_{1}\right)$ and a similarity factor $\left(f_{2}\right)$ to compare

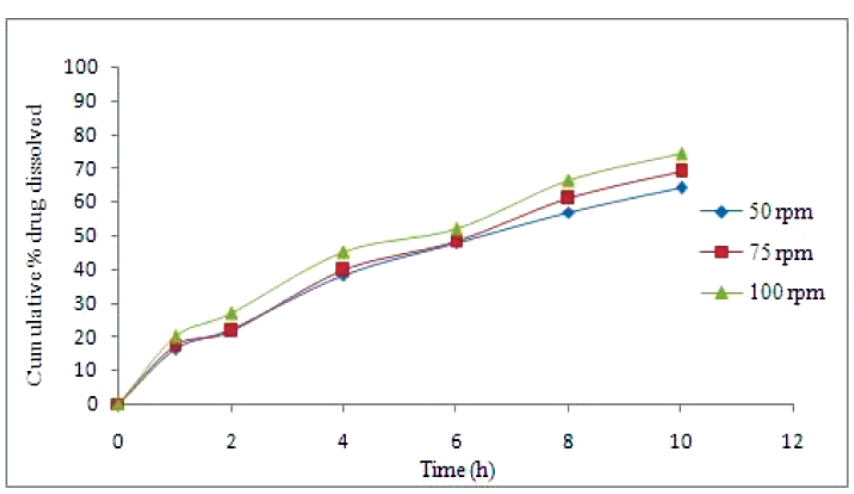

Figure 1. Comparative in vitro drug release profiles of Azukon at various agitation rates in $\mathrm{pH} 7.4$ phosphate buffer.

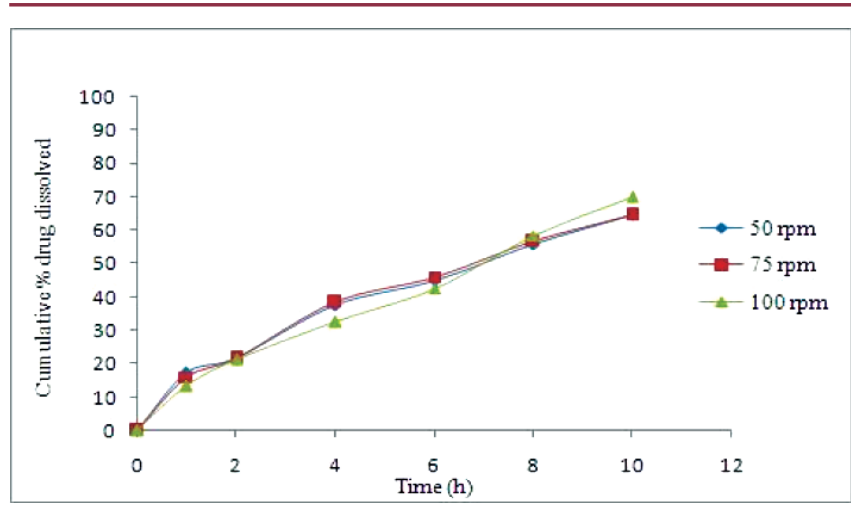

Figure 2. Comparative in vitro drug release profiles of Nuzide at various agitation rates in $\mathrm{pH} 7.4$ phosphate buffer.

dissolution profiles was used $(8,9)$. The difference factor $\left(f_{1}\right)$ calculates the percent difference between the two curves at each time point and is a measurement of the relative error between the two curves:

$$
f_{1}=\left\{\left[\sum_{t=1}^{n}\left|R_{t}-T_{t}\right|\right] /\left[\sum_{t=1}^{n} R_{t}\right]\right\} \times 100
$$

where $n$ is the number of time points, $R_{t}$ is the dissolution value of the reference (pre-change) batch at time $t$, and $T_{t}$ is the dissolution value of the test (post-change) batch at time $t$.

The similarity factor is calculated from the dissolution data generated in different dissolution media and at various revolutions. The similarity factor is calculated by following equation:

$$
f_{2}=50 \cdot \log \left\{\left[1+\frac{1}{n} \sum_{t=1}^{n}\left(R_{t}-T_{t}\right)^{2}\right]^{-0.5} \times 100\right\}
$$

where $n$ is the number of dissolution sampling times, and $R_{t}$ and $T_{t}$ are the individual or mean percent dissolved at each time point for the reference and test dissolution profiles, respectively.

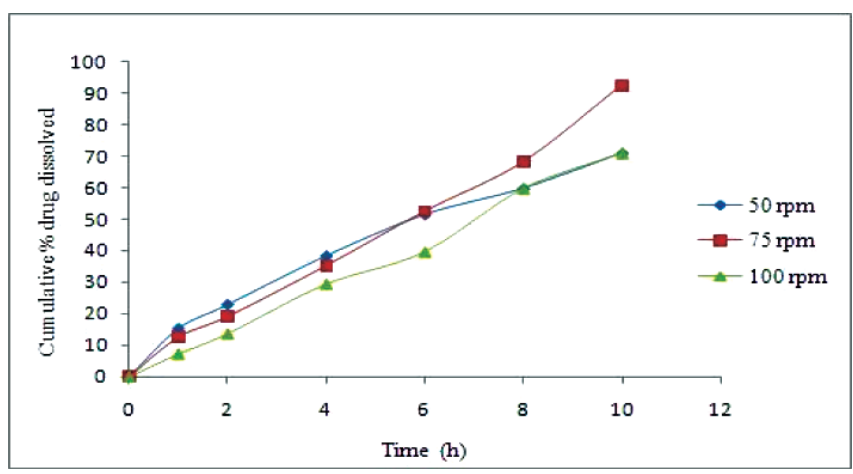

Figure 3. Comparative in vitro drug release profiles of Diamicron at various agitation rates in $\mathrm{pH} 7.4$ phosphate buffer. 


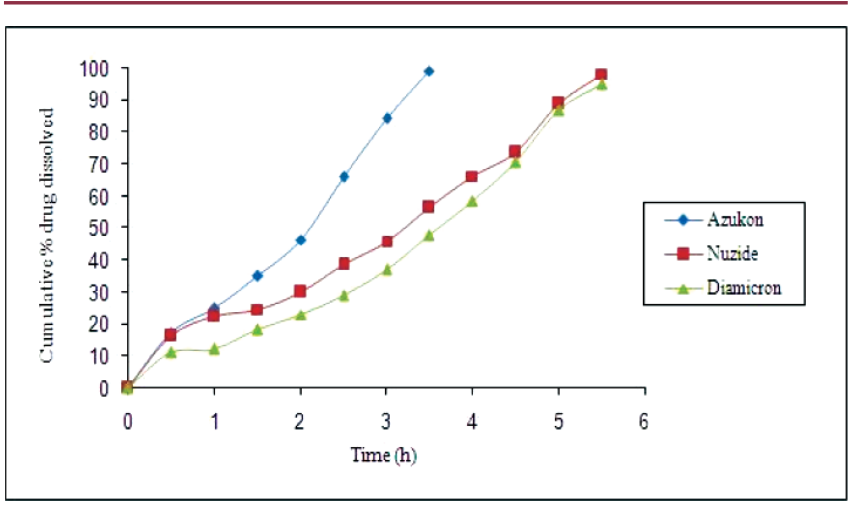

Figure 4. Comparative in vitro drug release profiles of various marketed brands of gliclazide MR tablets in $\mathrm{HCl}$ at $100 \mathrm{rpm}$.

\section{Statistical Interpretation of Dissolution Data}

The dissolution data were interpreted by statistical methods like analysis of variance (ANOVA) and $t$-test (10).

\section{RESULTS AND DISCUSSION}

The solubility data of gliclazide are shown in Table 1.The solubility of gliclazide was highest in $\mathrm{pH} 7.4$ phosphate buffer $(1.8415 \mathrm{mg} / \mathrm{mL})$. According to the USP, the quantity of medium used should not be less than three times that required to form a saturated solution of the drug substance. The ratio of saturation solubility to the dose in $900 \mathrm{~mL}$ of dissolution medium $\left(C_{s} / C_{\mathrm{D}}\right) \geq 3$ for $0.1 \mathrm{~N} \mathrm{HCl}$ (pH 1.2), distilled water ( $\mathrm{pH} 7)$, and phosphate buffer ( $\mathrm{pH}$ 7.4). Phosphate buffer ( $\mathrm{pH} 7.4)$ was a more suitable medium for dissolution study, as a higher value was obtained compared with other dissolution media.

In vitro drug release studies of commercial brands of gliclazide MR tablets (i.e., Azukon, Nuzide, and Diamicron) were performed in four different dissolution media $(0.1 \mathrm{~N}$ $\mathrm{HCl}, \mathrm{pH} 4.5$ acetate buffer, $\mathrm{pH} 7.4$ phosphate buffer, and distilled water) at $100 \mathrm{rpm}$. The influence of stirring speed on drug release rate was studied in $900 \mathrm{~mL}$ of phosphate buffer ( $\mathrm{pH}$ 7.4) employing three different agitation speeds $(50,75,100 \mathrm{rpm})$. Comparisons of the dissolution profiles

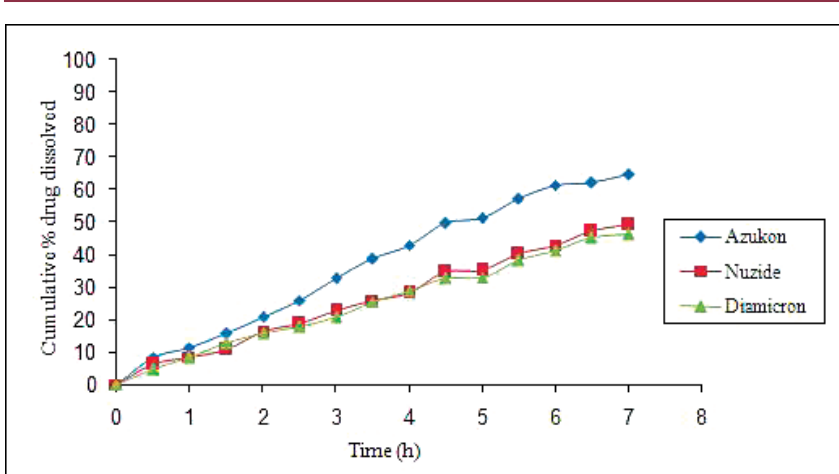

Figure 5. Comparative in vitro drug release profiles of various marketed brands of gliclazide MR tablets in pH 4.5 acetate buffer at $100 \mathrm{rpm}$.

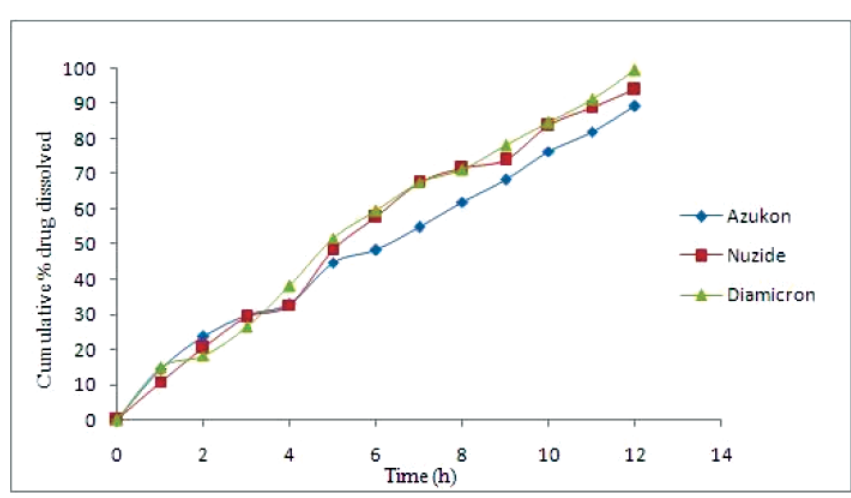

Figure 6. Comparative in vitro drug release profiles of various marketed brands of gliclazide MR tablets in water at $100 \mathrm{rpm}$.

of the three commercial brands of gliclazide in the four different media at three different agitation speeds are shown in Figures 1-7. The drug release from all formulations followed zero-order kinetics; however, for $\mathrm{pH} 4.5$ acetate buffer medium, the drug release rate followed first-order kinetics. The corresponding correlation coefficient values are shown in Tables 2 and 3. In vitro dissolution parameters $T_{50 \%}$ (time for dissolution of $50 \%$ of drug), $T_{90 \%}$ (time for dissolution of $90 \%$ of drug), and release rate ( $\mathrm{mg} / \mathrm{h}$ ) were calculated and are shown in Tables 2 and 3. Drug release was dependent on the composition of dissolution medium and agitation rate employed. Based on the drug release rate, the dissolution media can be ranked as $0.1 \mathrm{~N} \mathrm{HCl}(\mathrm{pH} 1.2)>$ distilled water $(\mathrm{pH} 7.0)>$ acetate buffer ( $\mathrm{pH} 4.5)>$ phosphate buffer ( $\mathrm{pH} 7.4)$. No correlation between the solubility and release rate of the drug in any of the buffers tested was observed. This may be due to the possible excipient effect on the solubility and dissolution rate of gliclazide. These experimental results suggest that $0.1 \mathrm{~N} \mathrm{HCl}$ is more suitable than $\mathrm{pH} 7.4$ phosphate buffer for dissolution studies of gliclazide modified-release formulations. It may be necessary to conduct further dissolution studies in $0.1 \mathrm{~N} \mathrm{HCl}$ to confirm the absence of dose dumping. The mechanism of drug

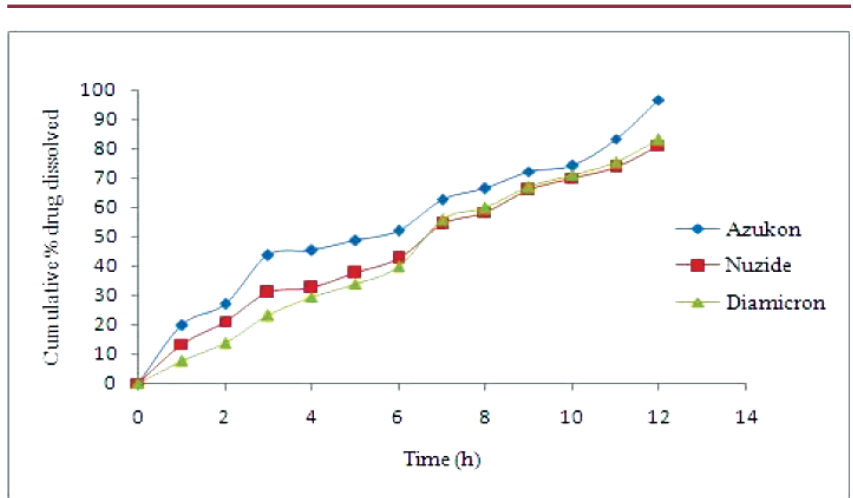

Figure 7. Comparative in vitro drug release profiles of various marketed brands of gliclazide MR tablets in pH 7.4 phosphate buffer at $100 \mathrm{rpm}$. 
Table 2. In Vitro Dissolution Parameters of Gliclazide MR Marketed Tablets at Various Agitation Rates in pH 7.4 Phosphate Buffer

\begin{tabular}{|c|c|c|c|c|c|c|c|c|c|c|c|c|c|}
\hline \multirow{2}{*}{$\begin{array}{l}\text { Agitation } \\
\text { Rate } \\
\text { (rpm) }\end{array}$} & \multirow[b]{2}{*}{ Brand } & \multicolumn{2}{|c|}{$\begin{array}{l}\text { Correlation coefficient } \\
\qquad\left(R^{2}\right)\end{array}$} & \multirow{2}{*}{$\begin{array}{c}\text { Release } \\
\text { rate } \\
(\mathrm{mg} / \mathrm{h})\end{array}$} & \multirow[b]{2}{*}{$\boldsymbol{T}_{50 \%}(\mathrm{~h})$} & \multirow[b]{2}{*}{$T_{90 \%}(\mathrm{~h})$} & \multirow{2}{*}{$\begin{array}{l}\text { Parameter for } \\
\text { Korsmeyer- } \\
\text { Peppas } \\
\text { equation }(n)\end{array}$} & \multicolumn{3}{|c|}{ Similarity factor $\left(f_{2}\right)$} & \multicolumn{3}{|c|}{ Difference factor $\left(f_{1}\right)$} \\
\hline & & Zero order & First order & & & & & $A B$ & BC & CA & $A B$ & BC & CA \\
\hline & Azukon & 0.9483 & 0.6072 & 2.1825 & 6.9 & 12.4 & 0.6201 & & & & & & \\
\hline \multirow[t]{3}{*}{50} & Nuzide & 0.9187 & 0.9875 & 3.168 & 6.6 & 21.8 & 0.5420 & 55.78 & 52.00 & 58.21 & 7.002 & 14.03 & 10.27 \\
\hline & Diamicron & 0.9771 & 0.8081 & 2.3714 & 6.3 & 11.4 & 0.6758 & & & & & & \\
\hline & Azukon & 0.9688 & 0.9351 & 2.2393 & 6.7 & 12.1 & 0.6663 & & & & & & \\
\hline \multirow[t]{3}{*}{75} & Nuzide & 0.9613 & 0.8831 & 2.0085 & 7.5 & 13.4 & 0.6183 & 71.58 & 45.72 & 49.95 & 6.42 & 17.16 & 14.10 \\
\hline & Diamicron & 0.9947 & 0.8355 & 2.6148 & 5.7 & 10.3 & 0.8015 & & & & & & \\
\hline & Azukon & 0.9368 & 0.6915 & 2.4598 & 6.1 & 11.0 & 0.5535 & & & & & & \\
\hline \multirow[t]{2}{*}{100} & Nuzide & 0.9774 & 0.9662 & 2.0717 & 7.2 & 13.0 & 0.6953 & 50.68 & 65.70 & 50.93 & 15.58 & 8.27 & 17.36 \\
\hline & Diamicron & 0.9962 & 0.9445 & 2.1129 & 7.1 & 12.8 & 0.9413 & & & & & & \\
\hline
\end{tabular}

A: Azukon; B: Nuzide; C: Diamicron

release from the marketed formulations was non-

Fickian diffusion, as the exponential coefficient of

Korsmeyer-Peppas equation was between 0.5 and 1.0.

To compare the release profiles of the marketed formulations, difference factors $\left(f_{1}\right)$ and similarity factors $\left(f_{2}\right)$ were calculated (Tables 2 and 3 ). Two dissolution profiles are considered similar when the $f_{1}$ value is closer to zero (i.e., $0-15$ ) and the $f_{2}$ value is greater than 50 . The $f_{2}$ values were greater than 50 at $100 \mathrm{rpm}$ in $\mathrm{pH} 7.4$ phosphate buffer and water (Table 2). More discrimination among the commercial brands was noticed when dissolution studies were conducted in $0.1 \mathrm{~N} \mathrm{HCl}$. The release rates observed from different commercial brands of gliclazide were treated statistically, and the data are depicted in Table 4. The release rate constant observed from different brands in various dissolution media was treated statistically with one-way ANOVA. A significant difference in release rate was noticed from these brands. To detect significant differences between two brands, the data were further analyzed with the Bonferroni multiple comparison test. The statistical results demonstrate that the differences in dissolution rate between each pair of brands are significant.

\section{CONCLUSION}

The rate of dissolution was dependent on stirring speed and composition of the dissolution medium. The dissolution medium $\mathrm{pH} 7.4$ phosphate buffer satisfied sink

Table 3. In Vitro Dissolution Parameters of Gliclazide MR Marketed Tablets in Different Dissolution Media at 100 rpm.

\begin{tabular}{|c|c|c|c|c|c|c|c|c|c|c|c|c|c|}
\hline \multirow{2}{*}{$\begin{array}{l}\text { Dissolution } \\
\text { medium }\end{array}$} & \multirow[b]{2}{*}{ Brand } & \multicolumn{2}{|c|}{$\begin{array}{c}\text { Correlation } \\
\text { coefficient }\left(R^{2}\right)\end{array}$} & \multirow{2}{*}{$\begin{array}{l}\text { Release } \\
\text { rate (mg/h) }\end{array}$} & \multirow[b]{2}{*}{$T_{50 \%}(h)$} & \multirow[b]{2}{*}{$T_{90 \%}(\mathrm{~h})$} & \multirow{2}{*}{$\begin{array}{c}\text { Parameter } \\
\text { for Korsmeyer- } \\
\text { Peppas } \\
\text { equation }(n)\end{array}$} & \multicolumn{3}{|c|}{ Similarity factor $\left(f_{2}\right)$} & \multicolumn{3}{|c|}{ Difference factor $\left(f_{1}\right)$} \\
\hline & & Zero order & First order & & & & & AB & BC & CA & AB & BC & CA \\
\hline \multirow{3}{*}{$\begin{array}{l}0.1 \mathrm{~N} \mathrm{HCl} \\
\mathrm{pH} 1.2\end{array}$} & Azukon & 0.9913 & 0.7740 & 8.0971 & 1.9 & 3.3 & 0.9121 & \multirow{3}{*}{30.55} & \multirow{3}{*}{58.21} & \multirow{3}{*}{25.38} & \multirow{3}{*}{37.98} & \multirow{3}{*}{12.75} & \multirow{3}{*}{52.67} \\
\hline & Nuzide & 0.9901 & 0.8041 & 5.078 & 3.0 & 5.3 & 0.7760 & & & & & & \\
\hline & Diamicron & 0.9747 & 0.8274 & 4.6287 & 3.2 & 5.8 & 0.9713 & & & & & & \\
\hline \multirow{3}{*}{$\begin{array}{l}\text { Acetate } \\
\text { buffer } \mathrm{pH} \\
4.5\end{array}$} & Azukon & 0.9918 & 0.9933 & 4.431 & 4.7 & 15.6 & 0.8571 & \multirow{3}{*}{45.86} & \multirow{3}{*}{77.54} & \multirow{3}{*}{43.50} & \multirow{3}{*}{28.88} & \multirow{3}{*}{6.86} & \multirow{3}{*}{32.06} \\
\hline & Nuzide & 0.9974 & 0.9890 & 2.1831 & 6.9 & 12.4 & 0.8552 & & & & & & \\
\hline & Diamicron & 0.9919 & 0.9970 & 2.580 & 8.1 & 26.8 & 0.8667 & & & & & & \\
\hline \multirow{3}{*}{$\begin{array}{l}\text { Distilled } \\
\text { water } \\
\text { pH } 7.0\end{array}$} & Azukon & 0.9877 & 0.8050 & 2.2979 & 6.5 & 11.7 & 0.7096 & \multirow{3}{*}{61.13} & \multirow{3}{*}{79.51} & \multirow{3}{*}{55.64} & \multirow{3}{*}{13.07} & \multirow{3}{*}{6.24} & \multirow{3}{*}{17.44} \\
\hline & Nuzide & 0.9871 & 0.9157 & 2.5248 & 5.9 & 10.7 & 0.8423 & & & & & & \\
\hline & Diamicron & 0.9883 & 0.8268 & 2.6444 & 5.7 & 10.2 & 0.8287 & & & & & & \\
\hline \multirow{3}{*}{$\begin{array}{l}\text { Phosphate } \\
\text { buffer pH } \\
7.4\end{array}$} & Azukon & 0.9368 & 0.6915 & 2.4598 & 6.1 & 11.0 & 0.5535 & \multirow{3}{*}{52.26} & \multirow{3}{*}{65.70} & \multirow{3}{*}{50.93} & \multirow{3}{*}{15.58} & & \\
\hline & Nuzide & 0.9774 & 0.9662 & 2.0717 & 7.2 & 13.0 & 0.6953 & & & & & 8.27 & 17.36 \\
\hline & Diamicron & 0.9962 & 0.9445 & 2.1129 & 7.1 & 12.8 & 0.9413 & & & & & & \\
\hline
\end{tabular}


Table 4. Statistical Treatment of Release Rates of Gliclazide from Commercial Brands

\begin{tabular}{|c|c|c|c|c|c|c|c|c|}
\hline \multirow[b]{3}{*}{ Dissolution Medium } & \multirow{2}{*}{\multicolumn{3}{|c|}{ Release Rate in Different Brands }} & \multirow{2}{*}{\multicolumn{2}{|c|}{ ANOVA at df $(2,6)$}} & \multicolumn{3}{|c|}{$t$-Test Summary } \\
\hline & & & & & & \multicolumn{3}{|c|}{ Bonferroni Multiple Comparison Test } \\
\hline & Azukon (A) & Nuzide (B) & Diamicron (C) & $\begin{array}{c}\text { Calculated } \\
\text { value }\end{array}$ & $P$ value & $A \& B$ & B \& C & $A \& C$ \\
\hline $0.1 \mathrm{~N} \mathrm{HCl} \mathrm{pH} 1.2$ & 8.0971 & 5.078 & 4.6287 & 11440 & $P<0.0001$ & $121.7(P<0.001)$ & $16.97(P<0.001)$ & $138.7(P<0.001)$ \\
\hline Acetate buffer $\mathrm{pH} 4.5$ & 4.431 & 2.1831 & 2.580 & 826.3 & $P<0.0001$ & $31.90(P<0.001)$ & $5.880(P<0.01)$ & $37.78(P<0.001)$ \\
\hline Distilled water $\mathrm{pH} 7.0$ & 2.2979 & 2.5248 & 2.6444 & 111.7 & $P<0.0001$ & $9.813(P<0.001)$ & $4.861(P<0.01)$ & $14.67(P<0.001)$ \\
\hline Phosphate buffer pH 7.4 & 2.4598 & 2.0717 & 2.1129 & 227.1 & $P<0.0001$ & $16.40(P<0.001)$ & $3.583(P<0.05)$ & $19.99(P<0.001)$ \\
\hline
\end{tabular}

conditions because the drug is highly soluble in it. More discrimination in dissolution profiles of gliclazide was observed from the dissolution studies conducted in $0.1 \mathrm{~N} \mathrm{HCl}$.

\section{REFERENCES}

1. Gray, V. A.; Brown, C. K.; Dressman, J. B.; Leeson, J. A New General Information Chapter on Dissolution. Pharm. Forum 2001, 27 (6), 3432-3439.

2. Sweetman, S.C., Ed. Martindale, the Complete Drug Reference, 36th ed.; Pharmaceutical Press: London, 2009; p 322.

3. Schernthaner, G.; Grimaldi, A.; Di Mario, U.; Drzewoski, J.; Kempler, P.; Kvapil, M.; Novials, A.; Rottiers, R.; Rutten, G. E.; Shaw, K. M. GUIDE study: double-blind comparison of once-daily gliclazide MR and glimepiride in type 2 diabetic patients. Eur. J. Clin. Invest. 2004, 34 (8), 535-542.

4. Wangnoo, S. K. Treatment of Type 2 diabetes with Gliclazide Modified Release $60 \mathrm{mg}$ in the Primary Care Setting of India. Int. J. Diabetes Dev. C. 2005, 25, 50-54.
5. Wit, J. B. M.; Doshi, H. A. Sustained-release formulation of gliclazide. Eur. Pat. Appl. 2181705, 2010.

6. Indian Pharmacopoeia; Government of India, Ministry of Health and Family Welfare, The Indian Pharmacopoeia Commission: Ghaziabad, India, 2007; Vol. 2.

7. The United States Pharmacopeia and National Formulary USP 25-NF 20; The United States Pharmacopeial Convention, Inc.: Rockville, MD, 2002.

8. Dissolution Testing of Immediate Release Solid Oral Dosage Forms; Guidance for Industry; U.S. Department of Health and Human Services, Food and Drug Administration, Center for Drug Evaluation and Research (CDER), U.S. Government Printing Office: Washington, DC, 1997.

9. Moore, J.W.; Flanner, H. H. Mathematical comparison of curves with an emphasis on in vitro dissolution profiles. Pharm. Technol. 1996, 20 (6), 64-74.

10. Soni, T.; Nagda, C.; Gandhi, T.; Chotai, N.P. Development of Discriminating Method for Dissolution of Aceclofenac Marketed Formulations. Dissolution Technol. 2008, 15 (2), 31-35. 